\title{
Search for optimum geometry of selected steel sandwich panel joints
}

\author{
Karol Niklas, MS.c. \\ Gdańsk University of Technology
}

\begin{abstract}
Application of steel sandwich panels to ship structures requires many problems to be solved. Joints between the panels as well as those between the panels and other structures is one of the more difficult problems associated with the structures in question. This paper presents the searching for process of optimum geometry of a panel-to-panel joint of longitudinal arrangement, performed by means of the ANSYS software. A configuration was searched for of parameters which can ensure as-low-as possible values of geometrical stress concentration coefficients at acceptable mass and deformations of the structure. Analysis of the obtained results made it possible to propose the optimum geometry of the considered joint.
\end{abstract}

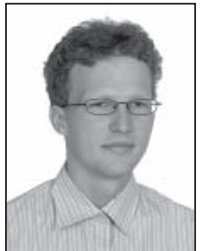

Keywords: steel sandwich panels, connection, optimization

\section{INTRODUCTION}

Ship structures are evolving with time. The need for increasing ship reliability, lifetime and safety results mainly from economic motivations. Along with increasing prices of steel and fuels, which exert high impact on decisions made in shipbuilding industry, one of the main impulses accelerating development of new, better structures is a tendency to make the shipbuilding time shorter and, at the same time, the time between its inspections and repairs longer. The pressure towards shortening the shipbuilding time is so high that shipyards have been transformed in sort of assembly factory of ship sections produced in smaller specialised cooperating plants. The next factor which is becoming more and more important in decisionmaking in the shipbuilding industry is ecological safety. The need for protection against ecological disasters provoked by ship accidents (collisions, groundings) was the main motivation for designing two-skin hulls. The development of the already existing structures is mainly done by evolution - structure improvement based on many-years' experience gained by the Classification Societies. In successive regulations higher and higher requirements are formulated (especially those concerning the ecology), with an intention to reduce the risk relating to ship operation. Along with the improvement of classical ship structure, the investigations are in progress over completely new structures which can be used as ship components. A list of these new structures includes steel sandwich panels, which reveal extremely favourable bending resistance and stiffness in relation to mass.

\section{STEEL SANDWICH PANELS}

Briefly speaking, the sandwich panels are two-skin structures revealing favourable stiffness and bending resistance in relation to mass. A concept of multi-layer structures has been well known for years and is in common use in building of plastic watercraft (laminate-foam-laminate, for instance). Employing advantageous multi-layer structures in shipbuilding was stopped for decades by technological problems (deformations generated during welding of extremely thin plates to their stiffeners, among others). And only recently the development of laser welding technology has made it possible to produce steel sandwich panels (Fig. 1).

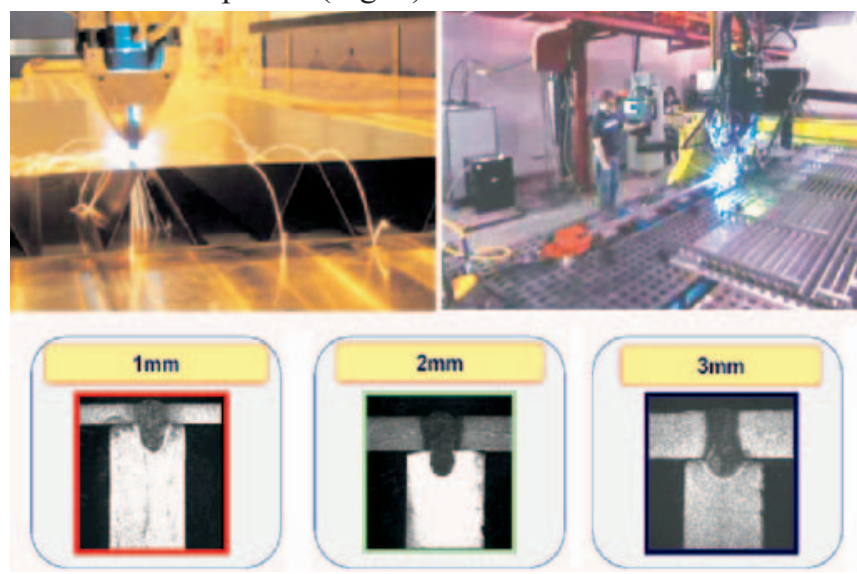

Fig. 1. Industrial production of steel sandwich panels [4] 
The laser welding technology was introduced to the industry about ten years ago. The need, having its origin in economic motivations, to reduce the mass of the structure is so high that it compensates high costs of laser welding.

But before making full use of the advantages offered by the steel sandwich panels, some problems concerning their application are to be solved. In particular, problems which stop their use as carrying elements of a structure concern $[1,2,3]$ :

$\star$ strength

$\star$ fatigue

$\star$ fire and acoustic insulation

$\star$ transmission of vibrations

$\star$ reaction to dynamic and point loads

$\star$ corrosion resistance

The use of sandwich panels in ship structures also requires analysing issues referring to the presence of cables and pipelines, communication holes, repairs of damages, operating control and utilisation. A separate group of problems, of high significance for the final shape of the structure, are joints between the panels, and between the panels and the classical structure.

\section{SELECTED PANEL JOINTS}

Joints between panels or between a panel and the classical structure are difficult problems affecting practical application of the panels. Solving a number of minor problems concerning these joints is a basic condition for their future use as components of larger structures. There are a variety of types of joints, including, for instance, panel-panel or panel-classic structure joints, cross-joints, panel height reduction, and panelsupport joint. One of more common constructional centres in the panel structure is the front panel-panel joint in longitudinal arrangement, in which the welds which link the panels are parallel to the direction of the stiffenings, see Fig. 2.

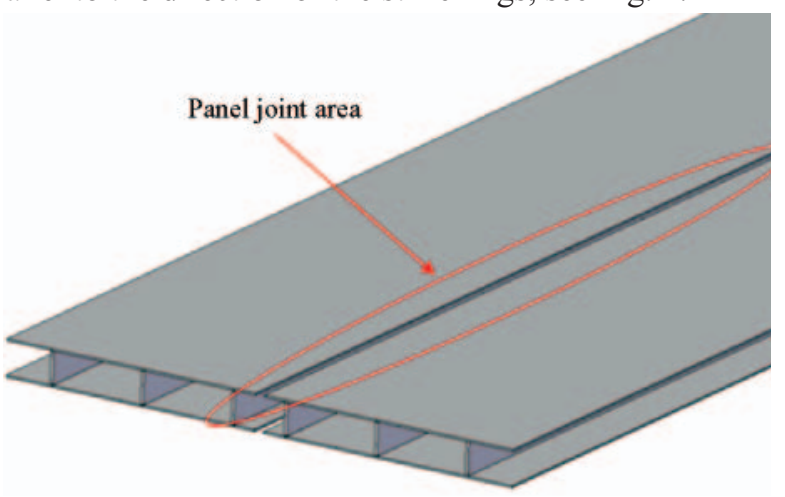

Fig. 2. Positions of I-core panels in longitudinal arrangement.

Numerous ways of execution of these joints are proposed. Sample (but not only possible) solutions are shown in Fig. 3. Individual proposals of these joints differ by mass, expected stiffness, cost, and time of execution. Within the framework of preliminary studies, two panel joints were selected for further examination from the point of view of technological realisability. In the assessment a number of factors were taken into account including: number of welds, preparing edges for welding, width of groove, assembly tolerance, ability to cut edges after fitting, fixing elements during the assembly, access to places be welded, smoothness of the joint, ability to prefabricate, and expected after-welding deformations. As a result, the joints which turned out most favourable from the point of view of technological realisability were those making use of cover plates and rectangular profiles, see Figs $3 \mathrm{c}$ and $3 \mathrm{~b}$.

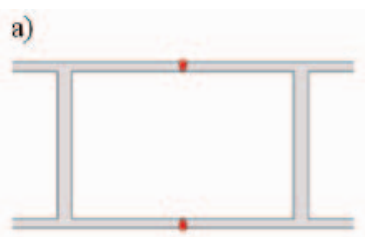

c)
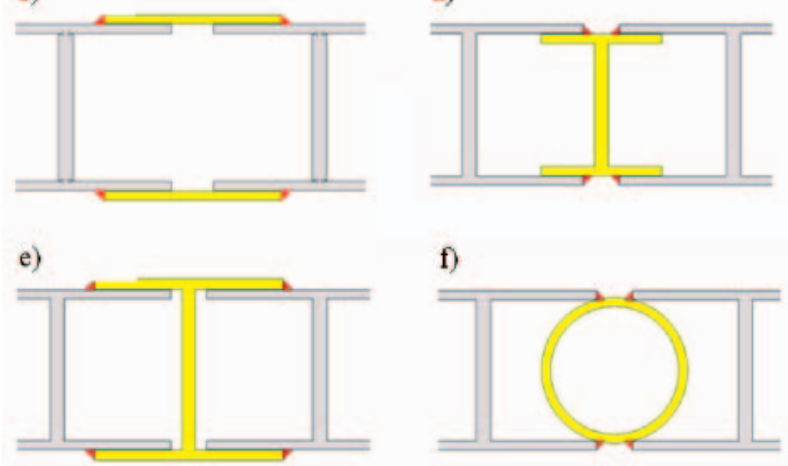

Fig. 3. Proposed joints

\section{SEARCH FOR OPTIMUM GEOMETRY OF THE SELECTED JOINTS}

To assess strength-to-mass ratios of the selected joint geometries, reduced stresses were calculated, using the Finite Element Method (FEM), in the joints loaded with stretching and compressing forces acting in the direction perpendicular to the joint.

The geometry of the selected joints was described using parameters shown in Fig. 4, in which the adopted coordinate system and the symmetry plane are marked as well. It was assumed that the joined panels have the same geometry. Because of repeatability of the joint structures, the "distance from panel end to first stiffener" parameter takes the value of $1 / 4$ or $1 / 2$ of the distance between the stiffeners. The parametric description was formulated in order to search for such a configuration of parameters for which the joint reveals the lowest coefficient of geometric concentration at relatively small mass and deformation. The reduced Mises stresses were used as the measure of joint's ability to carry the load (stretching or compressing force). The preferential criterion of joint evaluation was the stress, at an acceptable mass of the joint (up to $10 \%$ of panel mass). If, for some configurations of parameters, joints revealing similar stresses were obtained, the joint with smaller mass was selected. Two load conditions were assumed, which were stretching and compression in the panel plane.

\section{NUMERICAL MODELS OF THE JOINTS}

The calculations were performed in ANSYS environment. The assumed symmetry of the geometry and load, Fig. 5, has made it possible to analyse $1 / 4$ of the model, which considerably speeded up the calculations. To compensate possible effect of panel deflection on the operation of the joint, loads were applied at a distance equal to 2.5 distances between the stiffeners. Writing the geometry in the parametric form provided opportunities for performing a large series of calculations with changing combinations of parameters, without the necessity to build a new model for each combination. The modelling was done using the PLANE183 element - a plane solid-type element with the square shape function. The models had a carefully selected regular grid consisting of about 15 thousand elements. The side length of an individual element was approximately 

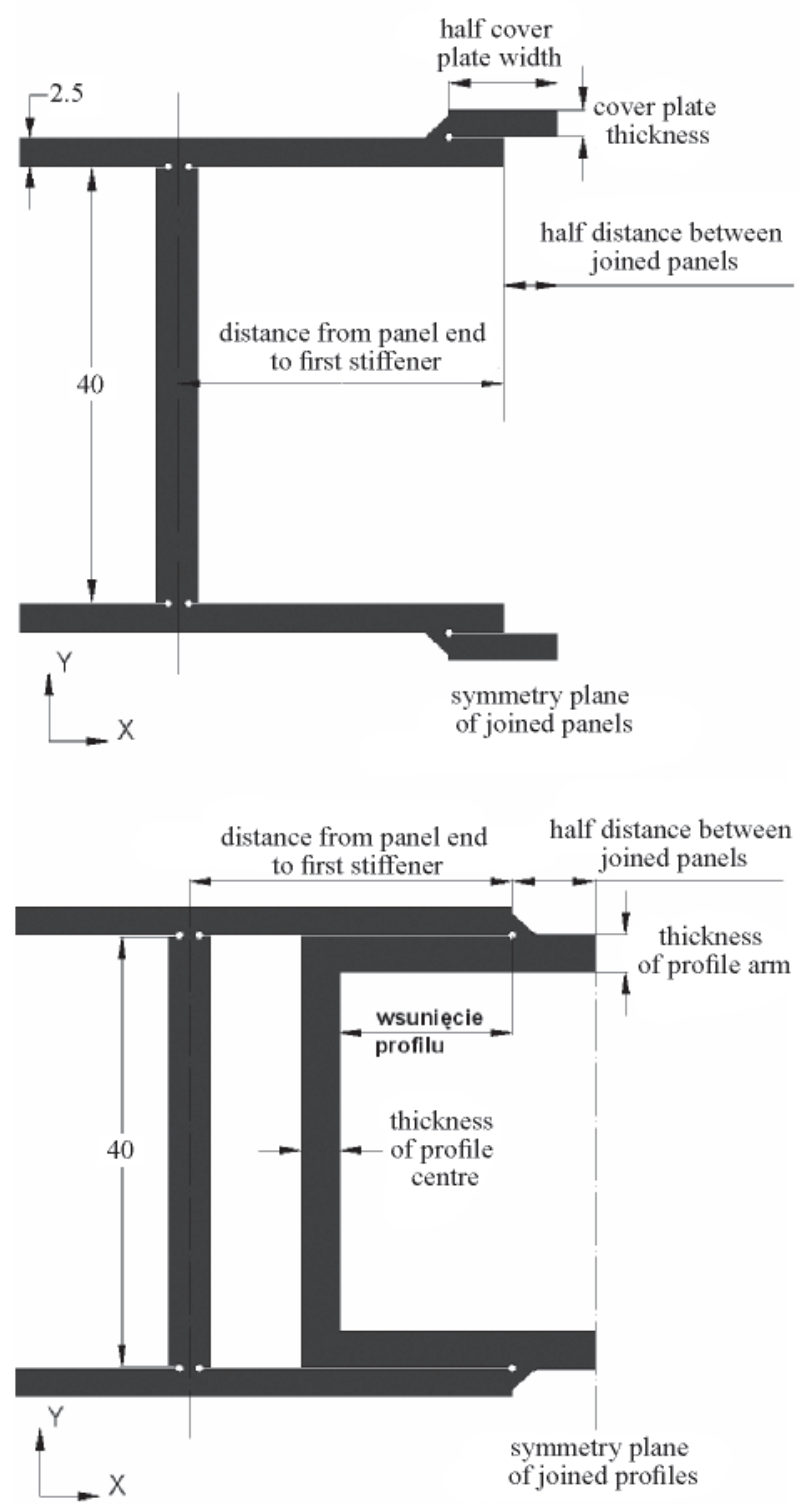

Fig. 4. Parameters describing the geometry of selected joints

equal to $0.1 \mathrm{~mm}$. The steel material constants were assumed for the isotropic model: $\mathrm{E}=2 \mathrm{e}^{5} \mathrm{MPa}$ and $v=0.3$.

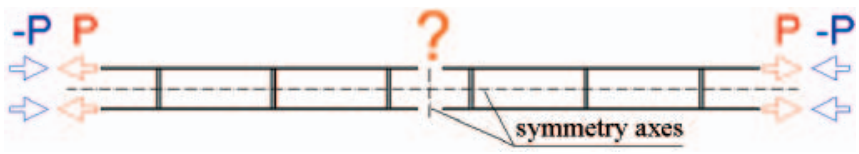

Fig. 5. Panel loaded with stretching force $(P)$ and compressing force (-P).

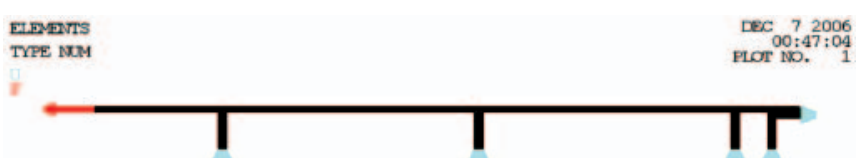

Fig. 6. Calculation model with assumed boundary conditions.

A sample model of the joint is given in Fig. 6, along with the applied boundary conditions and load. During numerical modelling of sandwich type structures, the most difficult and the most questionable model elements are laser welds. The technology of welding the stiffeners to the plating assumes laser welding from outside. Specific nature of the laser-welded joints is the reason why some gaps form between the stiffeners and the plating (their dimension in the discussed panel structures can approximately reach $0.1 \mathrm{~mm}$ ). In the ending areas of the welds technological notches are localised, which, when geometrically modelled in the numerical model, would lead to unrealistic, excessively high concentration of stresses $[5,6,7,8,9]$. For the computer model to reflect the real laser joints in a most realistic way, so-called circular concentrators are introduced to replace the welds in those places, see Fig. 7. These concentrators create geometric smoothening of the notches in the form of circles with specially selected dimensions and positions $[8,10,11,12]$. Of extremely high importance in weld modelling is taking into account different nature of laser weld operation compared to a joint made using a traditional technology. The laser weld are characteristic of three operation stages [1]: 1 - rotation of the joined elements; 2 - contact of the plating with the stiffener; 3 - common displacement of the plating and the stiffener in the same direction, but with the load carried by a much smaller cross-section than in classically welded structures. In order to control the nature of weld operation, relevantly defined "contact regions" have been introduced at selected stiffener edges.

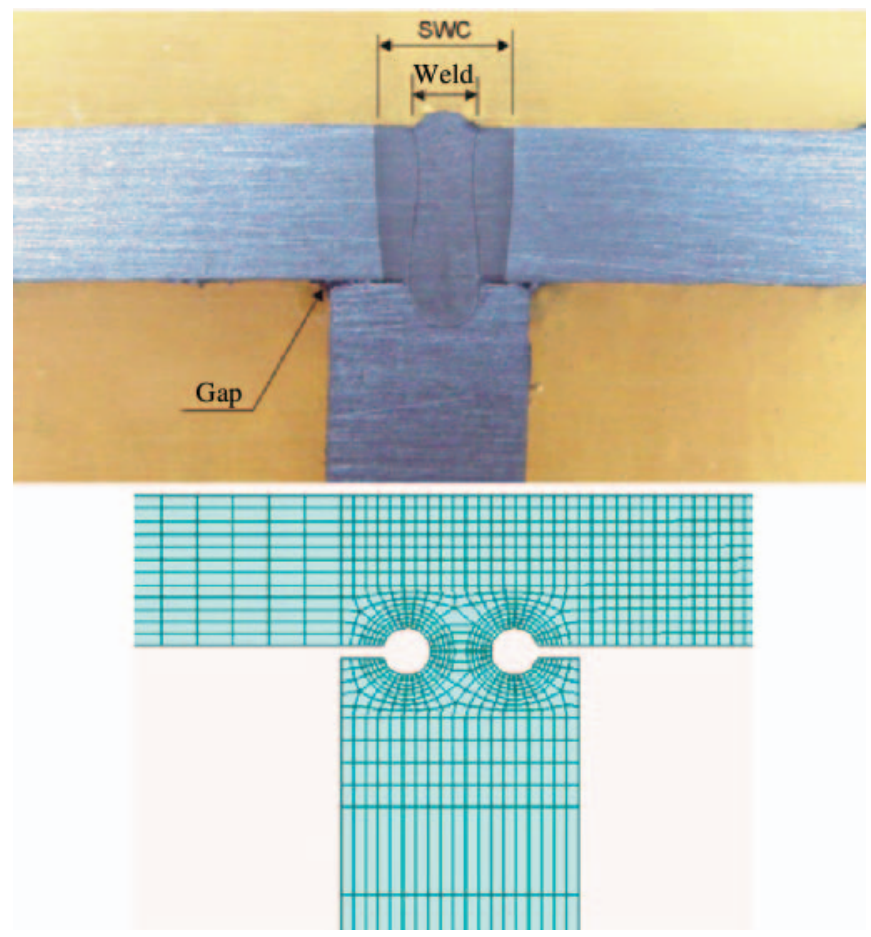

Fig. 7. Laser welded joint [1] and the FEM model.

\section{RESULTS}

To make the interpretation easier, the results of calculations are presented in the form of diagrams. In these diagrams the vertical axis represents the geometric concentration coefficient $\mathrm{Kg}$, calculated as the ratio of the maximum of the reduced Mises stress to the nominal stress. On the horizontal axes, different variable parameters describing the geometry of the joins are shown. Each configuration of parameters is represented by one point in the diagram. A huge volume of results has made it possible to build a surface which illustrates the effect of particular parameters on stress concentration. These surfaces were smoothed using the distance-weighted smallest square method, for which the calculations were done by the code "Statistica". The data discussed in the article solely refer to stresses.

Fig. 8 presents the results concerning the joint making use of cover plates. When increasing the "half cover plate width" parameter the stress concentration decreases and reaches a local minimum for $20-30 \mathrm{~mm}$. Further increasing of the plate width results in stress increase by about $40 \%$ in the vicinity of the first stiffener. Within the parameter range of $10-40 \mathrm{~mm}$ the 
deformations in the y-axis direction increase for stretching load and decrease for compression. When the width of the cover plate exceeds the distance to the first stiffener (40$50 \mathrm{~mm}$ ), the Mises stresses rapidly decrease. Deformations in the y-axis direction within this range decrease for the cover plate thickness of 2.5 and $3 \mathrm{~mm}$, and reach a local minimum for $50 \mathrm{~mm}$, but increase for the cover plate thickness of $2 \mathrm{~mm}$. More detailed analysis of the effect of particular parameters on stress and deformation of the joint has made it possible to select the most favourable configuration of parameters. The optimal configuration of parameters for the panel joints having the "distance from panel end to first stiffener" parameter equal to $1 / 4$ turned out to be the joint with the cover plate thickness equal to $2.5 \mathrm{~mm}$ and the parameter "half cover plate width" equal to $50 \mathrm{~mm}$.

\section{Diagram of geometric concentration stress coefficient $\mathrm{Kg}$ for cover plate panel joint with the distance form panel end to first stiffener equal to $1 / 4$}

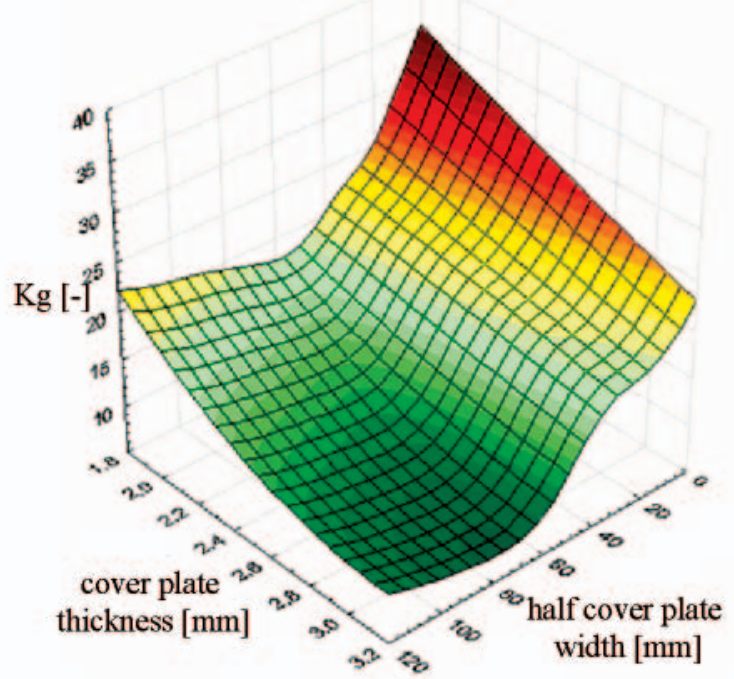

Diagram of geometric concentration stress coefficient $\mathrm{Kg}$ for cover plate panel joint with the distance form panel end to first stiffener equal to $1 / 2$

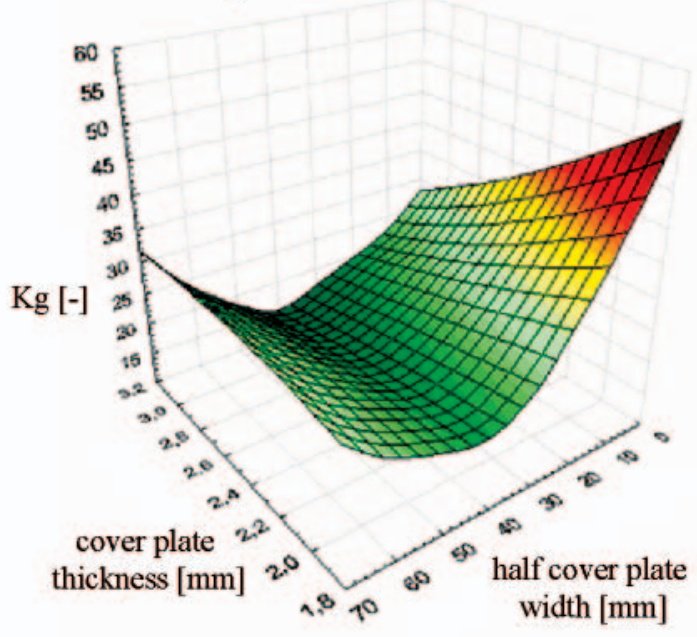

Fig. 8. Geometric concentration coefficient as a function of geometric parameters of the cover plate joint - stretching

For the cover plate panel joints with the "distance from panel end to first stiffener" parameter equal to $1 / 2$, the maximal values of the reduced Mises stresses their reach minima in the vicinity of the parameter value equal to $40 \mathrm{~mm}$ for all cover plate thickness cases when changing the "half cover plate width" parameter. Largest deformations are observed for the parameter equal to $30 \mathrm{~mm}$ when compressing. When compared to the $1 / 4$ case, panel joints with the "distance from panel end to first stiffener" parameter equal to $1 / 2$ reveal five times as large deformations in the $y$-axis direction during compression, at a comparable level of the maximum Mises stresses. The optimal configuration of parameters of the analysed joint is the cover plate joint with cover plate thickness equal to $3 \mathrm{~mm}$ and the "half coven plate width" parameter equal to $40 \mathrm{~mm}$.

Diagram of geometric concentration stress coefficient $\mathrm{Kg}$
for rectangular profile panel joint with the distance form panel end to first stiffener equal to $1 / 4$

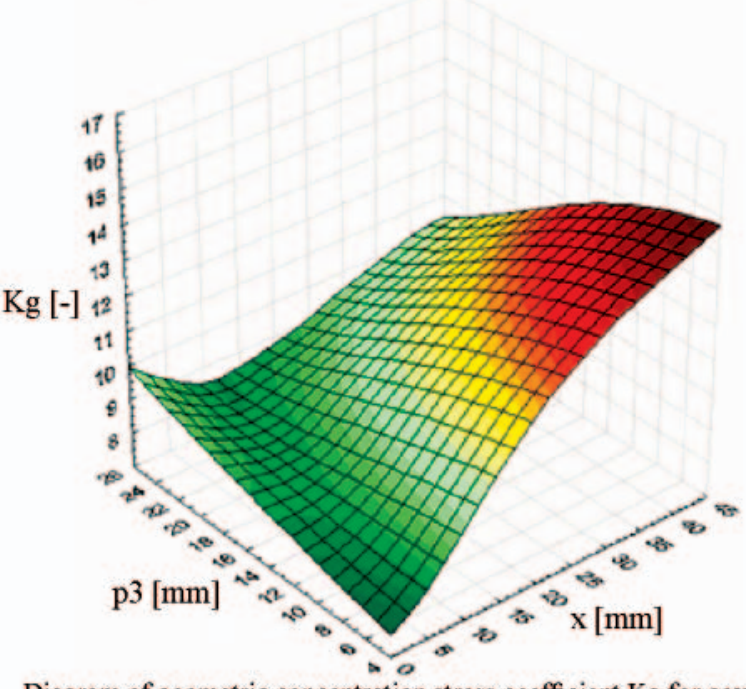

Diagram of geometric concentration stress coefficient $\mathrm{Kg}$ for cover plate panel joint with the distance form panel end to first stiffener equal to $1 / 4 . \mathrm{Kg}[-]=$ distance weighted smallest square smoothing

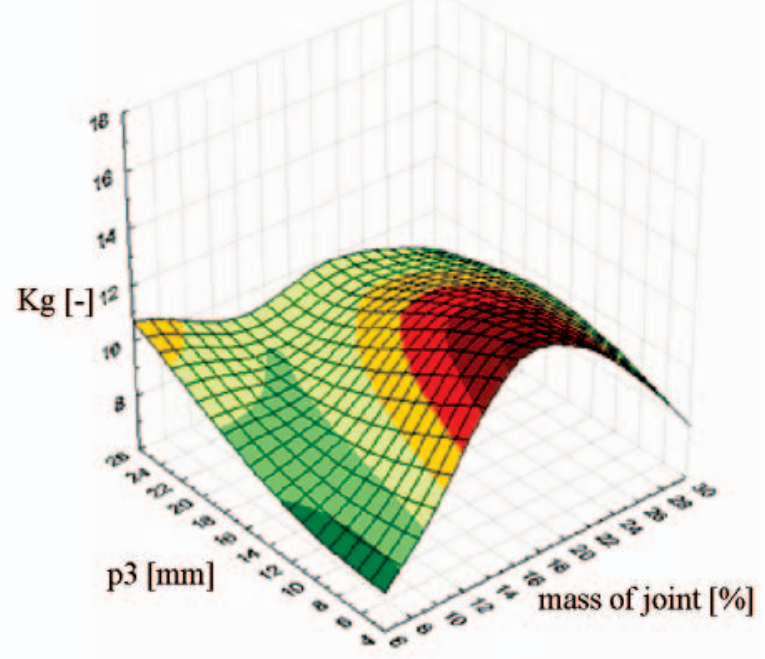

Fig. 9. Geometric concentration coefficient as a function of geometric parameters and mass of the rectangular profile joint - stretching

For rectangular profile panel joints with the "distance from panel end to first stiffener" parameter equal to $1 / 4$, the maximal values of the reduced Mises stresses and deformations in the $y$-axis direction depend much less on whether the joint is stretched or compresses than it was observed for the cover plate joints, Fig. 9. For small values of parameter p3 (profile insertion) the difference between deformations in the $\mathrm{x}$-axis and $y$-axis directions are visibly smaller that for the cover plate joints, but when the profile insertion increases these differences also increase (still remaining much smaller than for the cover plate joints). After comparing stresses and corresponding masses of particular joints we can see that for the same mass the maximum reduced Mises stresses change nearly by twice when changing the parameters. Also at the same stress level, changing parameters can result in mass change by as much as $20 \%$. The optimum configuration of parameters is a joint with the gap 
$\mathrm{x}=3.25 \mathrm{~mm}$, profile thickness equal to $3 \mathrm{~mm}$ and profile insertion equal to $5 \mathrm{~mm}$. This joint reveals the lower stress level at the mass equal to $9 \%$ of panel mass. Moreover, the deformations for these parameters also are the smallest.

Diagram of geometric concentration stress coefficient $\mathrm{Kg}$

for rectangular profile panel joint with the distance form panel end

to first stiffener equal to $1 / 2$. Distance weighted smallest square smoothing

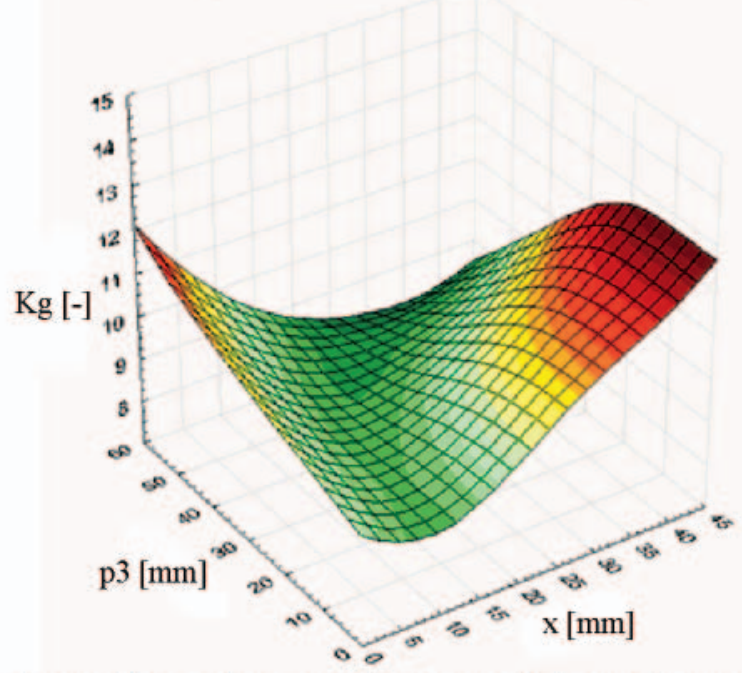

Diagram of geometric concentration stress coefficient $\mathrm{Kg}$ for cover plate panel joint with the distance form panel end to first stiffener equal to $1 / 4$. Distance weighted smallest square smoothing

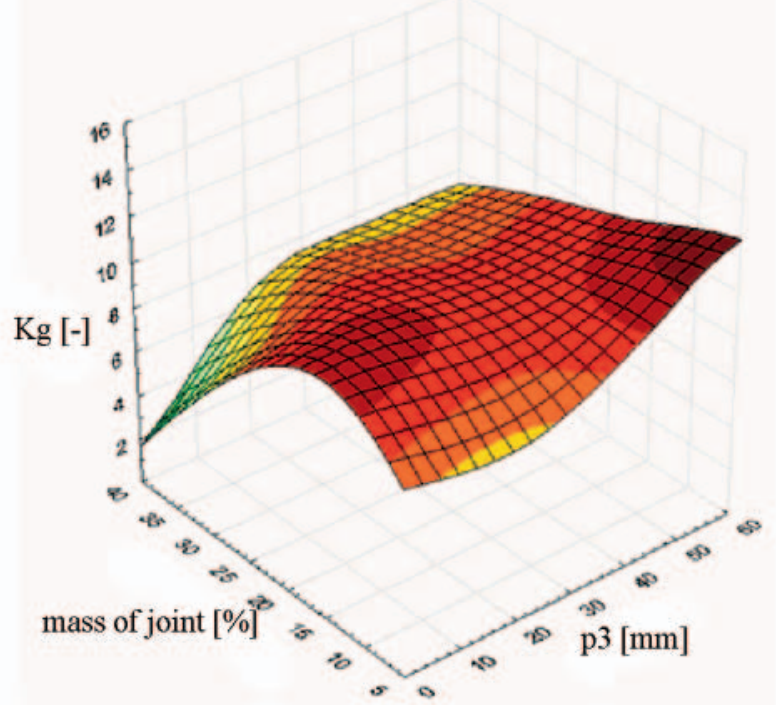

Fig. 10. Geometric concentration coefficient as a function of geometric parameters and mass of the rectangular profile joint - stretching

The results obtained for the rectangular profile panel joints with the "distance from panel end to first stiffener" parameter equal to $1 / 2$ are given in Fig. 10. The optimal configuration of parameters is the joint with the gap $\mathrm{x}=5 \mathrm{~mm}$ between the joined panels, profile thickness equal to $2.5 \mathrm{~mm}$ and profile insertion equal to $5 \mathrm{~mm}$. This joint reveals the lower stress level at the mass of joint equal to $8 \%$ of the panel mass.

The analysis of the above results makes it possible to formulate some summarising conclusions and compare the two examined types of joint: the cover plate joint and the rectangular profile joint, Fig. 11.

The cover plate panel joint reveals much higher geometric concentration coefficients. Although it has solution intervals characterised by much smaller mass, maximum stresses in those intervals reach several times as high levels as those observed in the rectangular profile joints. Also the maximum deformations are much smaller for the rectangular profile joints. To sum up, at comparable masses of the both joints (within the ranges of their optimal parameters) the rectangular profile joint secures much lower stresses and deformations, in particular in the $\mathrm{y}$-axis direction.

Comparison diagram of cover plate and rectangular profile joints. Panel joints with the distance from panel end to first stiffener equal to $1 / 4$ for stretching. Distance weighted smallest square smoothing

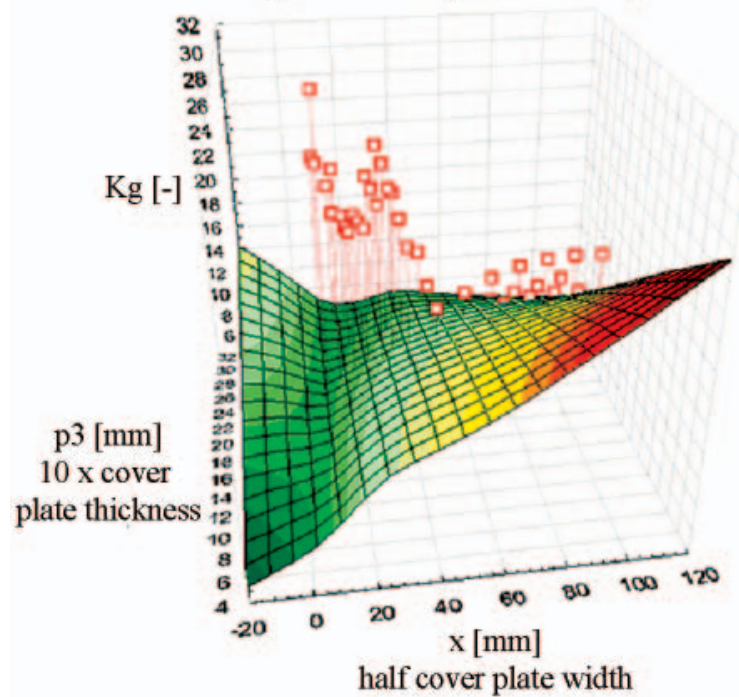

Comparison diagram of cover plate and rectangular profile joints. Panel joints with the distance from panel end to first stiffener equal to $1 / 2$ for stretching. Distance weighted smallest square smoothing

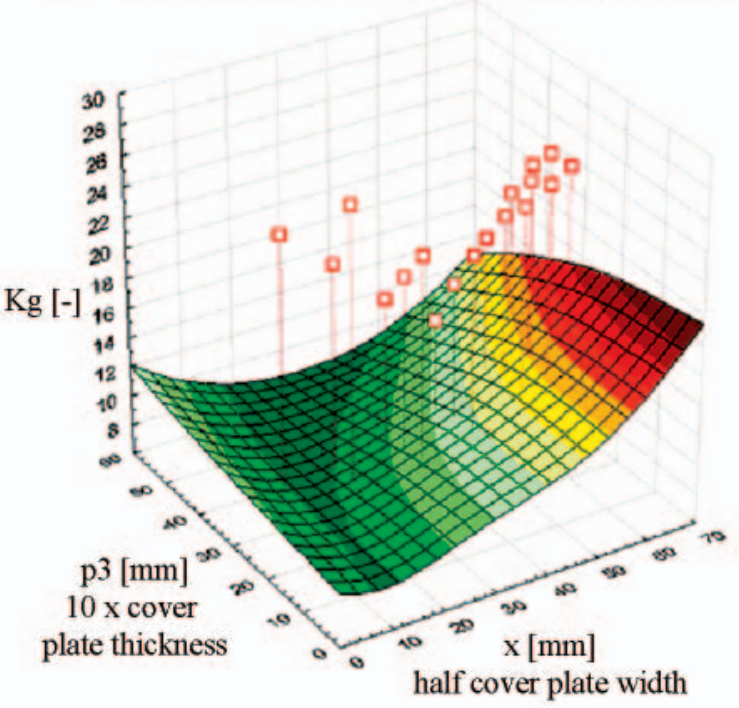

Fig. 11. Comparing the cover plate joint (points) and the rectangular profile joint (surface)

The final solution of the panel-panel heading joints in longitudinal arrangement is the rectangular profile joint shown in Fig. 12.

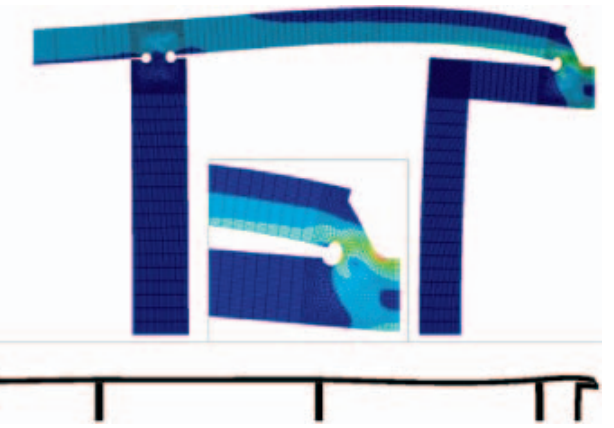

Fig. 12. Patterns of reduced Mises stresses and deformations (in 600:1 scale) for the optimum design (compression) 


\section{SUMMARY AND CONCLUSIONS}

The development of ship structures, dictated by strong economic factors, leads to better and better solutions. At the same time, concepts are formulated to replace fragments of classical ship structure by new-type elements. New solutions which can lead to remarkable reduction in mass and production time of the ship are steel sandwich panels. At present they cannot be used as ship bearers, because of the lack of relevant regulations of Classification Societies. But the economic pressure is so high that it forces increasing the use of panels in ship constructions. The panels are used for building between-decks, systems of ramps, decks of river vessels, balconies on passenger ships, stairways, and/or partition walls. Shipyards are becoming more and more similar to assembly factories using prefabricated elements produced by smaller specialised plants. This approach considerably reduces costs and, what is more important, the production time, which for numerous shipyards may be a decisive factor on the present-day competing market.

Certainly, new solutions bring new problems, which also are to be solved for the steel sandwich panels. One of basic problems refers to the joints between the panels, and between the panels and the classical ship structure. Statistically, the most frequently used type of joint is the panel-panel heading joint in the longitudinal arrangement. From among frequently proposed solutions of this joint two types were selected taking into account technological realisability, which were the cover plate joint and the rectangular profile joint. Parametric models were worked out for these two joints. A solution was searched which would secure relatively low coefficients of geometric concentration at small mass and acceptable deformation. The analysis of the obtained results made it possible to suggest the optimum joint geometry.

O Steel sandwich panels seem to grow in importance. They are likely to take a special place in the production of mega-yachts, the demand for which is enormously high, as their production making use of plastics is highly uneconomical.

\section{BIBLIOGRAPHY}

1. Janusz Kozak: Problems in assessing selected strength characteristics of steel two-skin ship structures. Publishers of the Gdansk University of Technology, Gdańsk 2005, (in Polish)

2. Romanoff J., Kujala P.: The Optimum Design for Steel Sandwich Panels Filled with Polymeric Foams. Proc. of 6th Int. Conf. on Fast Sea Transportation, Vol. 3, Southampton, 2001

3. Noury P., Hayman B., McGeorge D., Weitzenbock J.: Lightweight Construction for Advanced Shipbuilding - Recent Development. DNV internal report, 2002

4. Internet: http://sandwich.balport.com, http://www.plsystems.us, http://www.visotekinc.com, http://sandwich.balport.com, http://akseli.tekes.fi

5. Report No 01 on test of steel SANDWICH panels. Project: Application of Steel Sandwich Panels into Ship Structure EUREKA E! 3074 (ASPIS). Gdansk University of Technology, Faculty of Ocean Engineering and Ship Technology, Internal report No. 01/2004, 2004, (in Polish)

6. Report No. 07 on tests of steel SANDWICH panels. Project: Application of Steel Sandwich Panels into Ship Structure EUREKA E! 3074 (ASPIS). Gdansk University of Technology, Faculty of Ocean Engineering and Ship Technology, Internal report No. 07/2004, 2004 (in Polish).

7. Synthesis report test results. Project: Advanced Steel Sandwich Structures, Vth EC Framework Program SANDWICH, Internal report D44, 2003

8. Sandwich design principles and prototype designs, Pentti Kujala, internal/ confidential document.

9. Kozak J.: Strength Tests of Steel Sandwich Panel. PRADS 2004

10.Kujala P., Klanac A.: Analytical and Numerical Analyses of All Steel Sandwich Panels Under Uniform Pressure Load. Design 2002, Vol. 2, Dubrovnik, 2002

11.Allen H.G.: The analysis and design of structural sandwich panels. Pergamon Press, 1969

12.FEM analysis of a single SANDWICH panel. Project ASPIS EUREKA E!3074 (in Polish). Gdansk University of Technology, Faculty of Ocean Engineering and Ship Technology, Internal report, 2004.

\author{
CONTACT WITH THE AUTHOR \\ Karol Niklas, MS.c. \\ Faculty of Ocean Engineering \\ and Ship Technology \\ Gdansk University of Technology \\ Narutowicza 11/12 \\ 80-952 Gdansk, POLAND \\ e-mail: k.niklas@pg.gda.pl
}

